\title{
Steric vs electronic effects: a new look into stability of diastereomers, conformers and constitutional isomers
}

Received 00th January 20xx,

Sopanant Datta ${ }^{\mathrm{a}}$ and Taweetham Limpanuparb*a

Accepted 00th January 20xx

DOI: $10.1039 / \times 0 \times x 00000 x$

A quantum chemical investigation of the stability of compounds with identical formulas was carried out on 23 classes of halogenated compounds made of $\mathrm{H}, \mathrm{F}, \mathrm{Cl}, \mathrm{Br}, \mathrm{I}, \mathrm{C}, \mathrm{N}, \mathrm{P}, \mathrm{O}$ and $\mathrm{S}$ atoms. The prevalence of formula in which its $Z$ configuration, gauche conformation and meta isomer are the most stable forms is calculated and discussed. The prevalence data shows that in compounds made of carbon backbones, the electronic effect is weaker than the steric effect. The electronic factor is more important as the backbone atoms are replaced with atoms on the right and upper part of the periodic table.

Steric effects, non-bonded interactions leading to avoidance of spatial congestion of atoms or groups, are often the central theme in the discussion of stability of diastereomers, conformers and constitutional isomers. Reasonings based on steric effects are relatively intuitive and lead to a general conclusion that $E$ configuration, anti conformer and para isomer in diastereomers, conformers and constitutional isomers, respectively, should be the most stable forms. A number of findings to the contrary exist in the literature. Table 1 shows samples of experimental and theoretical evidence in which the $Z$ configuration, gauche conformer and meta isomer are the most stable forms. Even when steric reasoning correctly predicts the result, controversy ensues. For example, a number of organic chemistry textbooks attributed the relative stability of the staggered conformation of ethane to steric factor alone. The controversy of the ethane rotational barrier was discussed at length across the scientific community over eight years. ${ }^{1-8}$

Electronic effects, on the other hand, are relatively more difficult to apply to the three cases mentioned above. The reasoning for energy prediction often involves resonance structures $^{9-15}$ (mesomeric effect) or hyperconjugation ${ }^{16-18}$ of orbitals. Specific reasonings for each case are shown in Table 1.

\footnotetext{
a. Mahidol University International College, Mahidol University, Salaya, Nakhon Pathom 73170, THAILAND.

† Electronic Supplementary Information (ESI) available: See DOI: 10.1039/x0xx00000x
}

Table 1 Examples of exceptions to steric prediction with reasoning for carbon-backbone compounds in gas-phase*

\begin{tabular}{|c|c|}
\hline Case & Exceptions to steric prediction and reasoning \\
\hline 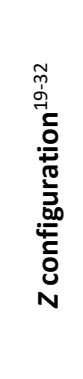 & $\begin{array}{ll}\mathrm{CHF}=\mathrm{CHF} \\
\mathrm{CHF}=\mathrm{CHCl} \\
\mathrm{CHF}=\mathrm{CHBr} & \begin{array}{l}\text { of electronic charges. When the donor and } \\
\mathrm{CHF}=\mathrm{CHI}\end{array} \\
\mathrm{acceptor} \text { are on the same side, the structure } \\
\mathrm{CHCl}=\mathrm{CHCl} & \begin{array}{l}\text { is more stable due to the interaction of } \alpha \text { and } \\
\mathrm{CHBr}=\mathrm{CHBr}\end{array} \\
& \begin{array}{l}\beta \text { substituents in the scheme. }{ }^{33} \text { Demiel } \\
\text { suggested that the more electronegative } \\
\text { atoms should be on the same side. }{ }^{11,13}\end{array}\end{array}$ \\
\hline 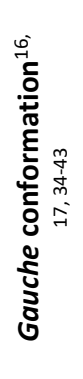 & $\begin{array}{l}\text { For } \mathrm{CH}_{2} \mathrm{~F}-\mathrm{CH}_{2} \mathrm{~F} \text {, the gauche form is preferred }{ }^{33} \text { due to the } \\
\text { hyperconjugative interaction described below. The } \\
\text { twofold }\left(\mathrm{V}_{2}\right) \text { potential actually has an energy minimum } \\
\text { when the torsional angle } \mathrm{F}-\mathrm{C}-\mathrm{C}-\mathrm{F} \text { is } \pm 90^{\circ} .{ }^{39} \text { Alternatively, } \\
\text { "bent bond" may offer an explanation for the } \\
\text { destabilization of the anti conformer. }{ }^{17,40,41}\end{array}$ \\
\hline 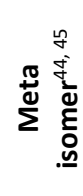 & $\begin{array}{l}\text { In most cases, meta isomers are the most } \\
\text { stable forms for dihalobenzenes. This } \\
\text { observation was attributed to the absence of } \\
\text { electronic interaction between the two } \\
\text { halogens at } 1,3 \text { - positions. }{ }^{45}\end{array}$ \\
\hline
\end{tabular}

* In the case of conformers, the rotational barrier is small such that the shift in equilibrium can be easily observed when polar solvents promote the interconversion of anti to gauche conformers.

There are many experimental and theoretical studies for other backbones such as $\mathrm{N}=\mathrm{N}^{32,46-51}, \mathrm{C}=\mathrm{N}^{52,53}, \mathrm{~N}=\mathrm{P}^{54}, \mathrm{C}=\mathrm{P}^{55}, \mathrm{P}=\mathrm{P}^{56,57}$ and N-N. ${ }^{58}$ 
Inspired by Bent's rule, ${ }^{59,60}$ whereby orbital hybridizations can explain trends of bond lengths and bond angles in a series of compounds correctly while the steric argument fails, in this communication, we want to find a unified model for energy prediction. The first step is to quantify the prevalence of formula in which the $Z$ configuration, gauche conformation and meta isomer are the most stable forms. All combinations of $\mathrm{H}$, $\mathrm{F}, \mathrm{Cl}, \mathrm{Br}$ and $\mathrm{I}$ as substituents with two of $\mathrm{C}, \mathrm{N}, \mathrm{P}, \mathrm{O}, \mathrm{S}$ or cyclopropane or benzene as the core structure were studied by our group. ${ }^{61-63}$ For the purpose of this communication, singlepoint electronic energy calculation at $\operatorname{CCSD}(\mathrm{T}) / 6-311++\mathrm{G}^{* *}$ were performed on previously optimized geometries. This applies to most compounds except for four groups that original MP2/6-311++G** energies were used as shown in Table 2 due to computational cost reasons. Raw Q-Chem ${ }^{64}$ output, detailed methodology and source codes can be found in the electronic supplementary information (ESI).

Table 2 Summary of class of compounds and quantum chemical calculation method

\begin{tabular}{|c|c|c|c|c|c|}
\hline Calculation method & \multicolumn{5}{|c|}{$\begin{array}{l}\text { Class of compound and } \\
\text { total number of structures }\end{array}$} \\
\hline \multirow{6}{*}{$\begin{array}{l}\operatorname{CCSD}(\mathrm{T}) / 6-311++\mathrm{G} * * / / \\
\operatorname{CCSD} / 6-311++\mathrm{G}^{* *}\end{array}$} & $\mathrm{C}=\mathrm{C}$ & $\mathrm{C}=\mathrm{N}$ & \multicolumn{2}{|c|}{$\mathrm{N}=\mathrm{N}$} & $0-0$ \\
\hline & 110 & 100 & \multicolumn{2}{|c|}{$30 *$} & 30 \\
\hline & & $C=P$ & \multicolumn{2}{|c|}{$\mathrm{N}=\mathrm{P}$} & O-S \\
\hline & & 100 & \multicolumn{2}{|c|}{50} & 50 \\
\hline & & & \multicolumn{2}{|c|}{$\mathrm{P}=\mathrm{P}$} & S-S \\
\hline & & & \multicolumn{2}{|c|}{30} & 30 \\
\hline \multirow{6}{*}{$\begin{array}{l}\operatorname{CCSD}(\mathrm{T}) / 6-311++\mathrm{G} * * / / \\
\mathrm{B} 3 \mathrm{LYP} / 6-311++\mathrm{G}^{* *}\end{array}$} & $\mathrm{C}-\mathrm{O}$ & \multicolumn{2}{|c|}{$\mathrm{N}-\mathrm{N}$} & \multicolumn{2}{|c|}{$\mathrm{N}-\mathrm{O}$} \\
\hline & 250 & \multicolumn{2}{|c|}{320} & \multicolumn{2}{|c|}{150} \\
\hline & C-S & \multicolumn{2}{|c|}{ N-P } & $\mathrm{N}-\mathrm{S}$ & $\mathrm{P}-\mathrm{O}$ \\
\hline & 250 & \multicolumn{2}{|c|}{600} & 150 & 150 \\
\hline & & \multicolumn{2}{|c|}{ P-P } & \multicolumn{2}{|c|}{ P-S } \\
\hline & & \multicolumn{2}{|c|}{320} & \multicolumn{2}{|c|}{150} \\
\hline \multirow{5}{*}{$\begin{array}{l}\mathrm{MP} 2 / 6-311++\mathrm{G} * * / / \\
\mathrm{MP} 2 / 6-311++\mathrm{G} * *\end{array}$} & $\mathrm{C}-\mathrm{C}$ & \multicolumn{2}{|c|}{$\mathrm{C}-\mathrm{N}$} & \\
\hline & 730 & \multicolumn{2}{|c|}{900} & & \\
\hline & & \multirow{3}{*}{\multicolumn{2}{|c|}{$\begin{array}{l}\text { C-P } \\
900\end{array}$}} & & \\
\hline & ${ }_{B}$ & & & & \\
\hline & 110 & & & & 30 \\
\hline
\end{tabular}

* In geometry optimization at CCSD/6-311++G** level of theory, $\mathrm{NBr}=\mathrm{N}$ and $\mathrm{NI}=\mathrm{NI}$ disintegrated into $\mathrm{N}_{2}$ and halogen moieties. Similarly, for conformers, some structures interconverted during the optimization process.

We followed the standard definition of $E$ and $Z$ configuration for diastereomers as per the CIP priority rules of the International Union of Pure and Applied Chemistry. The relative bulkiness of all substituents (covalent or Van der Waals radii) in this study also follows the priority rule. Therefore, the $E$ configuration is predicted to be the most stable form by steric effects.

In a similar manner, for gauche and anti conformers, the torsional angle of the highest-priority substituents per CIP rules from the two ends of the molecule are considered. The angles of $-120^{\circ}$ to $120^{\circ}$ are treated as gauche and the angles of $-180^{\circ}$ to $-120^{\circ}$ and $120^{\circ}$ to $180^{\circ}$ are counted as anti. Unlike the previous definition of gauche effect, ${ }^{65}$ ambiguous cases are not considered for simplicity. For example, conformers of $\mathrm{CBr}_{2} \mathrm{Cl}$ $\mathrm{CF}_{2} \mathrm{Cl}$ are not considered since the presence of the two $\mathrm{Br}$ atoms as the highest priority atoms on the left leads to an ambiguity in labelling the conformations as gauche or anti.

For constitutional isomers of benzene, we apply the nomenclature ortho, meta, para to highly substituted benzenes for consideration if it can be done by using the two highest priority substituents without ambiguity for all isomers in an empirical formula. For example, $\mathrm{C}_{6} \mathrm{~F}_{4} \mathrm{Cl}_{2}$ isomers can be considered but $\mathrm{C}_{6} \mathrm{Cl}_{4} \mathrm{~F}_{2}$ isomers are not included in our analysis.

As per the definition above, steric effects therefore predict that the anti conformer and the para isomer in this communication are the most stable forms in a similar fashion to the $E$ configuration. Deviations from these expectations are tabulated as the percentage of total cases as shown in Figure 1. These are regarded as cases in which electronic effects are in the counteracting direction and are relatively stronger than steric effects.

Figure 1 Percentage of deviations from steric predictions for each class of compound

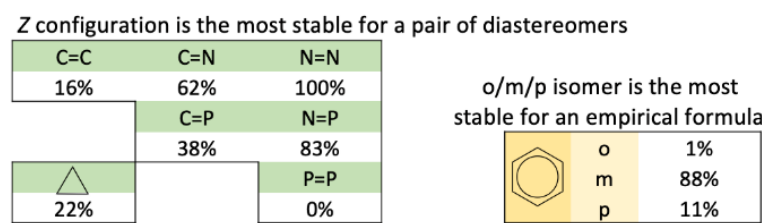

Gauche conformation is the most stable for a compound

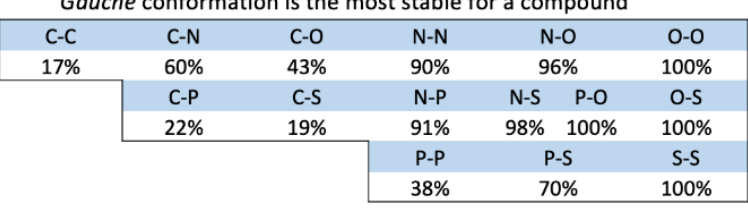

To the best of our knowledge, this is the first attempt to estimate the prevalence of these effects. Many chemistry textbooks ${ }^{66-68}$ mention the relative stability of cis-trans isomers but neglect to mention these phenomena probably for simplicity or because the phenomena were thought to be rare. From Figure 1, the prevalence rate is relatively small but still significant i.e. $16 \%$ for $Z$ configuration and $17 \%$ for gauche conformation for compounds of carbon backbone. The rate increases to almost all of the cases when the backbone is made of atoms from the right and upper part of the periodic table.

We note that there are borderline cases for both experimental and computational results as the difference in energy can be extremely small. For the example of $\mathrm{CHBr}=\mathrm{CHBr}$ in Table 1 , the gas-phase experimental value for a configuration conversion from $E$ to $Z$ is $-100 \pm 160 \mathrm{cal} / \mathrm{mol}$ in one source ${ }^{19}$ and revised to $90 \pm 240 \mathrm{cal} / \mathrm{mol}$ in another. ${ }^{25}$ The present $\operatorname{CCSD}(\mathrm{T})$ electronic energy agrees with the later source that the $E$ configuration is more stable. However, similar to the conformer case mentioned in the footnote of Table 1 , the $Z$ structure is 
preferred in liquid. ${ }^{25}$ For uncertainty in computational results, the change in level of theory from MP2 to $\operatorname{CCSD}(T)$ in Figure 1 leads to a change in prevalence rate of up to $6 \%(\mathrm{P}=\mathrm{S})$.

For halobenzenes, meta isomers are not the exception but the majority of the most stable forms. Similar observations in dioxin-like compounds confirm this meta preference e.g. for the first few chlorine substitutions to polychlorinated biphenyls (PCB), polychlorinated dibenzo- $p$-dioxins (PCDD) and polychlorinated dibenzofurans (PCDF), the most stable chlorination occurs at meta positions with respect to the other ring. ${ }^{69}$

Figure 2 Unified models to predict the occurrence of preference for $Z$ configuration, gauche conformation and meta isomer

\begin{tabular}{|c|}
\hline $\begin{array}{l}\text { Regression } \\
\text { (Quantitative) }\end{array}$ \\
\hline 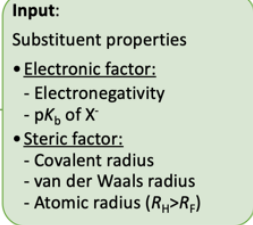 \\
\hline $\begin{array}{l}\text { Result: } \\
\text { - Regression coefficients }\left(c_{i}\right) \\
\text { - Correlation }\left(R^{2}\right)\end{array}$ \\
\hline
\end{tabular}

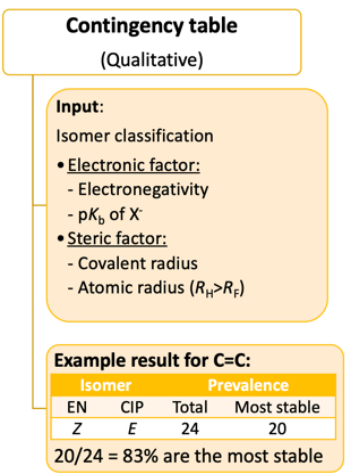

The roles of steric and electronic factors in determining the stability of structures were explored using quantitative and qualitative models as shown in Figure 2. Details of all models are given in the ESI.

The quantitative models were constructed using a multiple linear regression analysis to predict electronic energy based on steric and electronic factors. Given that the electronic energy of a structure is determined primarily from the steric and electronic interactions among its substituents, the aim of this analysis is to depict the counteracting effects of steric and electronic interactions. Multiple linear regression was obtained from a combination of up to three-body terms of one representation of steric interaction and one representation of electronic interaction. To represent steric interaction, one from three measures of atomic size, covalent radius, van der Waals radius and atomic radius was used; the first two exhibit the typical trend of $R_{\mathrm{H}}<R_{\mathrm{F}}<R_{\mathrm{Cl}}<R_{\mathrm{Br}}<R_{\text {l }}$ whereas the last leads to the trend of $R_{\mathrm{F}}<R_{\mathrm{H}}<R_{\mathrm{Cl}}<R_{\mathrm{Br}}<R_{\mathrm{l}}$. To represent electronic interactions, one from two measures, electronegativity (Pauling scale) and $\mathrm{p} K_{\mathrm{b}}$ values of the conjugate base $\mathrm{X}^{-}$was used.

Our expectation was that the energy from the electronic terms for $Z$, gauche or meta structures should be lower than those for their counterparts, and vice versa for the steric terms. However, with different combinations of representation of steric and electronic interaction and different possible mathematical models up to three-body terms, there is no unified model that works as expected for all 23 classes of compounds.
For the qualitative model, contingency tables composed of different structure classification were constructed. Structures were classified by taking into account both steric and electronic factors. These two factors may both stabilize the same structure or may compete to have the stronger one to determine the most stable structure. In the former case, we should be able to use known steric and electronic models to predict the most stable structures for all compounds. Ours models include electronegativity and $\mathrm{p} K_{\mathrm{b}}$ values of the conjugate base to represent electronic factors and covalent radius and atomic radius to represent steric factors. (Since only the ranking is important here, van der Waals radius is not needed.) Classification of isomers was done using a combination of a steric and an electronic factor in a similar manner to how atomic numbers are used in the CIP rule. Contingency tables were made by finding the total number of each kind of structure and the number of cases in which it is the most stable form. As an example, in Figure 2, there are a total of $24 \mathrm{C}=\mathrm{C}$ structures classified as $Z$ using electronegativity values $\left(Z_{\mathrm{EN}}\right)$ and $E$ using covalent radius $\left(E_{\mathrm{RC}}\right)$ of which 20 are the most stable, leading to $20 / 24=83 \%$ of $Z_{\mathrm{EN}}$ and $E_{\mathrm{CIP}}$ compounds being the most stable of their isomers. If Demiel's hypothesis ${ }^{11,}{ }^{13}$ about high electronegativity atom model (explained in Table 1 ) were true, the number would have been $100 \%$. Other three combinations were also explored and consistent $100 \%$ for all classes of compounds could not be attained. Figure 1 can be considered as the results from the simplest model of the four where electronic factor $\left(\mathrm{p} K_{\mathrm{b}}\right)$ and steric factor (covalent radius) have exactly opposing trends. In this model only, we do not have an expectation of $100 \%$ in diastereomer contingency tables.

Deviations from expected results in both quantitative and qualitative models above could be explained or addressed in three ways. Firstly, there could be a third factor affecting the results. For example, the deviation from idealised geometry was considered by performing both quantitative and qualitative analyses on the unoptimized structures (by using standard bond lengths and bond/torsional angles). Improved trends were observed as shown in the ESI. Secondly, the description of electronic contribution may be improved to better model the results. Thirdly, in cases of conformers and constitutional isomers, only considering the pair of highest priority substituents has an inherent flaw and may not reflect the summative effect of all substituents.

In conclusion, the phenomenon ${ }^{8}$ of cis effect, gauche effect and meta effect which we called them in this communication $Z$ configuration effect, gauche conformation effect and meta isomer effect are real and not negligible. It is very important to be apprehensive when steric reasonings are used to make stability predictions with halogen substituents. The data presented should lead to a renewed interest in a unified model to rationalize electronic effects in these model compounds.

The authors extend their appreciation to NRCT and Mahidol University for research funding. We are grateful to Pierre Priest, Peter Gill, Junming Ho, Kridtin Chinsukserm and Wanutcha 
Lorpaiboon for discussion and analysis in the early phase of this project.

\section{Author Contributions}

S.D. and T.L. contributed equally. All authors have given approval to the final version of the manuscript.

\section{Conflicts of interest}

There are no conflicts to declare.

\section{Notes and references}

1. V. Pophristic and L. Goodman, Nature, 2001, 411, 565-568.

2. F. Weinhold, Nature, 2001, 411, 539-541.

3. P. R. Schreiner, Angew. Chem., 2002, 41, 3579-3582.

4. F. M. Bickelhaupt and E. J. Baerends, Angew. Chem., 2003, 42, 4183-4188.

5. F. Weinhold, Angew. Chem., 2003, 42, 4188-4194.

6. Y. Mo, W. Wu, L. Song, M. Lin, Q. Zhang and J. Gao, Angew. Chem., 2004, 43, 1986-1990.

7. Y. Mo and J. Gao, Acc. Chem. Res., 2007, 40, 113-119.

8. S. Liu, N. Govind and L. G. Pedersen, J. Chem. Phys., 2008, 129, 094104.

9. L. Pauling, L. O. Brockway and J. Y. Beach, J. Am. Chem. Soc., 1935, 57, 2705-2709.

10. K. S. Pitzer and J. L. Hollenberg, J. Am. Chem. Soc., 1954, 76, 14931496.

11. A. Demiel, J. Org. Chem., 1962, 27, 3500-3504.

12. G. B. Savitsky and K. Namikawa, J. Phys. Chem., 1963, 67, 27542756.

13. A. Demiel, J. Org. Chem., 1965, 30, 2121-2126.

14. J. Reuben and A. Demiel, J. Chem. Phys., 1966, 44, 2216-2217.

15. J. T. Waldron and W. H. Snyder, J. Am. Chem. Soc., 1973, 95, 5491 5495.

16. N. C. Craig, A. Chen, K. H. Suh, S. Klee, G. C. Mellau, B. P. Winnewisser and M. Winnewisser, J. Am. Chem. Soc., 1997, 119, 4789-4790.

17. L. Goodman, H. Gu and V. Pophristic, J. Phys. Chem. A, 2005, 109, 1223-1229.

18. I. V. Alabugin, G. dos Passos Gomes and M. A. Abdo, Wiley Interdiscip. Rev. Comput. Mol. Sci., 2019, 9, e1389.

19. J. M. Dowling, P. G. Puranik, A. G. Meister and S. I. Miller, J. Chem. Phys., 1957, 26, 233-240.

20. H. G. Viehe, Chem. Ber., 1960, 93, 1697-1709.

21. N. C. Craig and E. A. Entemann, J. Am. Chem. Soc., 1961, 83, 30473050.

22. H. G. Viehe and E. Franchimont, Chem. Ber., 1963, 96, 3153-3158.

23. N. Craig, Y. S. Lo, L. Piper and J. C. Wheeler, J. Phys. Chem., 1970, 74, 1712-1727.

24. N. C. Craig, D. A. Evans, L. G. Piper and V. L. Wheeler, J. Phys. Chem., 1970, 74, 4520-4527.

25. N. C. Craig, L. G. Piper and V. L. Wheeler, J. Phys. Chem., 1971, 75, 1453-1460.

26. D. Dixon, T. Fukunaga and B. E. Smart, J. Am. Chem. Soc., 1986, 108.

27. J. B. P. da Silva, J. Braz. Chem. Soc., 2000, 11, 219-223.

28. R. Kanakaraju, K. Senthilkumar and P. Kolandaivel, J. Mol. Struct. THEOCHEM, 2002, s 589-590, 95-102.

29. N. A. Pradie and H. V. Linnert, J. Phys. Chem. A, 2007, 111, 48364848.

30. D. Feller, K. A. Peterson and D. A. Dixon, J. Phys. Chem. A, 2011, 115, 1440-1451.

31. S. Jenkins, S. R. Kirk, C. Rong and D. Yin, Mol. Phys., 2013, 111, 793805.

32. D. Banerjee, A. Ghosh, S. Chattopadhyay, P. Ghosh and R. K. Chaudhuri, Mol. Phys., 2014, 112, 3206-3224.
33. E. L. Eliel, S. H. Wilen and L. N. Mander, Stereochemistry of Organic Compounds, Wiley, New York, USA, 1994

34. P. R. Rablen, R. W. Hoffmann, D. A. Hrovat and W. T. Borden, J. Chem. Soc., Perkin Trans. 2, 1999, 1719-1726.

35. F. R. Souza, M. P. Freitas and R. Rittner, J. Mol. Struct. THEOCHEM, 2008, 863, 137-140.

36. D. Y. Buissonneaud, T. van Mourik and D. O'Hagan, Tetrahedron, 2010, 66, 2196-2202.

37. J. C. R. Thacker and P. L. A. Popelier, J. Phys. Chem. A, 2018, 122 1439-1450.

38. F. A. Martins and M. P. Freitas, Eur. J. Org. Chem., 2019, 2019, 64016406.

39. L. Radom, W. A. Lathan, W. J. Hehre and J. A. Pople, J. Am. Chem. Soc., 1973, 95, 693-698.

40. R. C. Bingham, J. Am. Chem. Soc., 1976, 98, 535-540.

41. K. B. Wiberg, M. A. Murcko, K. E. Laidig and P. J. MacDougall, J. Phys. Chem., 1990, 94, 6956-6959.

42. C. Thiehoff, Y. P. Rey and R. Gilmour, Isr. J. Chem., 2017, 57, 92-100.

43. D. O'Hagan, Chem. Soc. Rev., 2008, 37, 308-319.

44. J. Cioslowski, G. Liu and D. Moncrieff, J. Phys. Chem. A, 1997, 101, 957-960.

45. E. Taskinen, Struct. Chem., 2000, 11, 293-301.

46. G. T. Armstrong and S. Marantz, J. Chem. Phys., 1963, 38, 169-172.

47. N. Wiberg, G. Fischer and H. Bachhuber, Angew. Chem., 1977, 16, 780-781.

48. K. Nordhoff and E. Anders, J. Org. Chem., 1999, 64

49. G. S. Tschumper, M. C. Heaven and K. Morokuma, Chem. Phys. Lett., 2003, 370, 418-424.

50. P. R. P. Barreto, A. F. A. Vilela and R. Gargano, Int. J. Quantum Chem., 2005, 103, 659-684.

51. T. Yamamoto, D. Kaneno and S. Tomoda, J. Org. Chem., 2008, 73, 5429-5435

52. J. M. Howell, J. Am. Chem. Soc., 1976, 98, 886-887.

53. H. G. Li, C. K. Kim, B. S. Lee, C. K. Kim, S. K. Rhee and I. Lee, J. Am. Chem. Soc., 2001, 123, 2326-2333.

54. X. Zeng, H. Beckers and H. Willner, Angew. Chem., 2009, 48, 48284831.

55. M. T. Nguyen, A. Van Keer and L. G. Vanquickenborne, J. Organomet. Chem., 1997, 529, 3-14.

56. T. Lu, A. C. Simmonett, F. A. Evangelista, Y. Yamaguchi and H. F. Schaefer, J. Phys. Chem. A, 2009, 113, 13227-13236.

57. S. Vogt-Geisse and H. F. Schaefer, J. Chem. Theory Comput., 2012, 8 1663-1670.

58. H. B. Schlegel and A. Skancke, J. Am. Chem. Soc., 1993, 115, 74657471.

59. H. A. Bent, Chem. Rev., 1961, 61, 275-311.

60. I. V. Alabugin, S. Bresch and M. Manoharan, J. Phys. Chem. A, 2014, 118, 3663-3677.

61. K. Chinsukserm, W. Lorpaiboon, P. Teeraniramitr and T. Limpanuparb, Data Brief, 2019, 27, 104738.

62. T. Limpanuparb, S. Datta, K. Chinsukserm and P. Teeraniramitr, Data Brief, 2020, 30, 105442.

63. S. Datta and T. Limpanuparb, Data Brief, 2020, 30, 105386

64. Y. Shao, Z. Gan, E. Epifanovsky, A. T. Gilbert, M. Wormit, J. Kussmann, A. W. Lange, A. Behn, J. Deng and X. Feng, Mol. Phys. 2015, 113, 184-215.

65. S. Wolfe, Acc. Chem. Res., 1972, 5, 102-111.

66. R. H. Petrucci, F. G. Herring, J. D. Madura and C. Bissonnette, General chemistry: principles and modern applications, Pearson, New Jersey, USA, 2017.

67. T. W. G. Solomons, C. B. Fryhle and S. A. Snyder, Organic Chemistry, John Wiley \& Sons, Inc., New Jersey, USA, 2016.

68. P. Vollhardt and N. Schore, Organic Chemistry: Structure and Function, W. H. Freeman and Company, New York, USA, 2018.

69. S. Datta and T. Limpanuparb, Molecules, 2020, 25, 5697. 